\title{
Use it or lose it: a qualitative study of the maintenance of physical activity in older adults
}

Asiya Maula ${ }^{1 *} \mathbb{D}$, Natasher LaFond ${ }^{1}$, Elizabeth Orton ${ }^{1}$, Steve lliffe ${ }^{2}$, Sarah Audsley ${ }^{1}$, Kavita Vedhara ${ }^{1}$ and Denise Kendrick ${ }^{1}$

\begin{abstract}
Background: Lack of physical activity (PA) is a recognised global public health problem, which is increasing in prevalence with a detrimental impact on the pattern of disease worldwide. In the UK, older adults comprise the most sedentary group, with only $57 \%$ of males and $52 \%$ of females aged $65-74$ years and $43 \%$ of males and $21 \%$ of females aged 75-84 years meeting PA recommendations.

PA confers multiple health benefits including increased stamina, muscle, bone and joint strength, increased independence and reduced risk of falls in old age. Despite benefits experienced during time-limited PA programmes, increased PA is not always continued. This study aimed to provide a better understanding of PA maintenance behaviours in older people.
\end{abstract}

Methods: Face to face semi-structured interviews were conducted with adults who completed one of two strength and balance exercise programmes as part of the ProAct65+ trial: group (FaME) and home based (OTAGO) exercises. Five GP practices in Nottingham and Derby were recruited and invited people aged 65 years and older who met eligibility criteria. Interviews were conducted in participants' homes. Interviews explored PA levels pre and post intervention, perceived health benefits, facilitators, barriers and use of technology for PA maintenance. The interviews were transcribed verbatim and analysed using framework analysis and the software NVivo10.

Results: Fifteen participants from each intervention group were interviewed. The FaME group consisted of 10 females and 5 males, age range of 70-88 years. The OTAGO group consisted of 12 females and 3 males aged 7295 years. Important themes identified were physical, social, psychological and environmental facilitators and barriers. These included increased physical autonomy, enjoyment, positive evaluation of the activity and physical benefits, importance of social interaction, positive feedback, development of behaviour considered normal or habitual, motivation and self-efficacy. Some participants used technologies not included in the original interventions, like pedometers and smart phones to motivate themselves.

Conclusions: A range of modifiable factors influence continued participation in PA at the end of exercise programmes. The findings from this study will inform the commissioning and quality improvement of future PA programmes and development of an intervention to enhance continuation of PA after exercise interventions in older adults.

Keywords: Physical activity, Maintenance, Older adults, Qualitative study, Community exercise programmes

\footnotetext{
* Correspondence: Asiya.maula@nottingham.ac.uk

${ }^{1}$ School of Medicine, University of Nottingham, Floor 14 Room 1401, Tower

building, University Park, Nottingham NG7 2RD, UK

Full list of author information is available at the end of the article
}

(c) The Author(s). 2019 Open Access This article is distributed under the terms of the Creative Commons Attribution 4.0 International License (http://creativecommons.org/licenses/by/4.0/), which permits unrestricted use, distribution, and reproduction in any medium, provided you give appropriate credit to the original author(s) and the source, provide a link to the Creative Commons license, and indicate if changes were made. The Creative Commons Public Domain Dedication waiver (http://creativecommons.org/publicdomain/zero/1.0/) applies to the data made available in this article, unless otherwise stated. 


\section{Background}

Physical inactivity is 'the non-achievement of physical activity guidelines' [1] defined by Public Health England as 'engaging in less than 30 minutes of physical activity per week' [2]. It is the fourth leading risk factor for global mortality [3], responsible for $9 \%$ of premature deaths worldwide in 2008 [4]. Inactivity increases susceptibility to chronic conditions (e.g. type II diabetes, osteoporosis, cancer, cardiovascular disease, falls) which are major causes of morbidity, mortality and health resource use worldwide [5-10]. It is estimated that a reduction in inactivity would lessen the burden of the leading non communicable diseases (which include coronary heart disease, type 2 diabetes, breast and colon cancers) by between 6 and $10 \%$ worldwide and improve life expectancy [4].

The population of older adults is increasing alongside the prevalence of chronic diseases. In the UK, between 2001 and 2011, the population of adults aged 65 years and over increased by approximately 1 million [11]. Worldwide the number of adults aged 60 years and over is estimated to increase $56 \%$ between 2015 and 2030 [12]. In the UK, older adults comprise the most sedentary group. Current recommendations for physical activity (PA) amongst older adults are $150 \mathrm{~min}$ of moderate to vigorous aerobic exercise and 2 strength and balance exercise sessions per week [13]. However, only 57\% of males and $52 \%$ of females aged $65-74$ years and $43 \%$ of males and $21 \%$ of females aged 75-84 years self-report activities that meet PA recommendations [14].

Regular PA in older people is associated with increased functional independence, stamina (the ability to sustain prolonged physical effort) [15], muscle strength, bone and joint health and improvements in blood pressure. Other benefits include reduced risk of falls and fractures, cardiovascular events, pain and disability from arthritis, symptoms of depression and anxiety and maintenance of cognitive function [6, 16-18]. Many of the positive effects from endurance and resistance type exercise decline within 2 weeks if activity levels are markedly reduced and disappear over 2-8 months if PA levels are not recommenced [18], highlighting the importance of PA maintenance. Whilst there is evidence that promoting physical activity for older people can be effective [19-22], evidence relating to which intervention components help to maintain increases in PA after taking part in structured community-based exercise programmes is much sparser, with only a small number of studies reporting effective PA maintenance [23-33]. Over the last 30 years, numerous theories of physical activity behavioural change have been proposed [34]. We did not choose to focus on one specific behaviour change theory in the design and conduct of our study, instead we use a range of behaviour change theories to interpret our findings.
This study aimed to identify the facilitators and barriers to the maintenance of PA amongst older people after taking part in a three-arm trial of time-limited community-based exercise programmes (Falls Management Exercise programme (FaME) or home based exercise Programme (OTAGO) or usual care) in the ProAct65+ multicentre randomised controlled trial [35]. The ProAct65+ trial recruited community dwelling adults aged $\geq 65$ years, who were independently mobile (with or without a walking aid) and physically able to take part in group exercise. The OTAGO and FaME programmes were both designed for use in community settings, specifically for people aged 65 and over. As well as being designed to reduce falls, both are based on the components of fitness and principles of programming for all older adults (i.e. warm up, mobility, stretches, strength and balance, endurance and a cool-down) and have all the elements of training appropriate for that age group. Exercises are tailored to the individual's ability and health need. FaME includes weekly exercise classes, and both FaME and OTAGO include home exercises. The primary outcome of the ProAct65+ trial was selfreported physical activity, and falls were a secondary outcome. The trial demonstrated a significant increase in the proportion of older people undertaking at least 150 min of moderate to vigorous physical activity per week and a significant reduction in the incidence of falls in the FaME arm compared to the control group, 12 months after the intervention. Full details of the trial are available at: www.ncbi.nlm.nih.gov/books/NBK262322/

The findings from this qualitative study can help us understand why falls prevention exercises can increase general physical activity and could inform the design and delivery of future exercise programmes for older adults.

\section{Methods}

The 10 GP practices in Nottingham and Derby which recruited the largest numbers of participants to the ProAct65+ trial were approached to take part in the study, the first five practices who consented to participate were recruited. The ProAct65+ trial included a sixmonth intervention period, with follow-up 24 months after the end of the intervention. The intervention period for individual trial participants ended between January 2010 and March 2012. Interviews for the qualitative study took place between December 2015 and March 2016, i.e. between 4 and 6 years post intervention. Practices sent out study invitations including a participant information sheet to ProAct $65+$ trial participants who were eligible for the current study (eligibility criteria are shown in Table 1) with reminders 3 weeks later to non-responders.

Maximum variation sampling was used to ensure diversity across the FaME or OTAGO programmes, 
Table 1 Inclusion Criteria

Inclusion criteria

Previous ProAct65+ participant in either the FaME or OTAGO arms of the trial

Able to provide written informed consent

65 years old and above

English speaking

Study recruitment considered appropriate by GP and would not cause undue distress to participant

Not diagnosed with a terminal illness

gender, age, previous falls and fear of falling. Responders meeting sampling criteria were provided with further study information by telephone, with subsequent semistructured face to face interviews conducted at the participants' own home. Written informed consent for the interview was obtained face-face at the participants own home prior to the interview. Withdrawal was permitted at any time point during the study, with consent sought to use the data collected thus far.

Interview questions were based on a review of the relevant literature, expert opinion of project team members and advice from patient and public involvement (PPI) representatives, as recommended by INVOLVE where research is conducted 'with' or 'by' the public [36]. Interviews sought views about the exercise programme, current PA and PA pre-and post ProAct65+ trial participation, perceived facilitators and barriers to PA maintenance, use of technology in keeping physically active and influence from family or friends on PA (See Additional file 1). The first two interviews served as pilot interviews, after which, the question order was modified to improve participant understanding of the questions, no other changes were made. Pilot interview data was included in the analysis. To ensure consistency of interview technique, interviewer shadowing took place where one researcher conducted the interview and the second observed, followed by debriefing. This process was repeated with roles reversed until both interviewers were satisfied with the consistency of their interview technique. Interviews were conducted by one of three researchers (NL, AM, SA). Interviews were fully completed by all participants.

Participants completed a questionnaire at the interview, including questions on FRAT [37] (fall risk assessment tool), physical activity [38], concern about falling [39] and general health [40]. Interviews were recorded on a digital audio recorder and transcribed verbatim. The transcribed data was managed using NVivo10 and analysed using framework analysis [41]. Immersion of the data ensued to allow familiarization [42]. The transcripts were then coded identifying recurrent themes. The analysis framework was developed based on the codes identified. The first researcher coded all transcripts, nineteen were coded by the second researcher ensuring consistency of themes identified with any discrepancies discussed and resolved. In addition, a PPI representative read and coded three transcripts followed by discussion with researchers, this allowed for incorporation of a lay perspective on themes identified.

\section{Results \\ Demographics}

There were 122 ProAct65+ participants in the five recruited practices, 99 of whom met eligibility criteria and were invited to participate in the study. Fifty-three (54\%) replied expressing interest. Thirty interviews were conducted between December 2015 and March 2016. Each interview lasted up to $1 \mathrm{~h} 20 \mathrm{~min}$. Thematic saturation was achieved with the number of interviews completed.

Characteristics of study participants are shown in Table 2. Four main themes were identified: physical, psychological, social and environmental with several subthemes within each. Quotes accompanying each section can be found in Table 3 .

\section{Physical facilitators and barriers}

Maintenance of PA resulted in improved physical autonomy. Participants were more likely to engage in and maintain PA when they positively evaluated its benefits. The physical benefits reported were similar in both FaME and OTAGO programmes and included improvements in suppleness, balance, mobility, strength and confidence related to a reduction in falls. These represented core intrinsic rewards from taking part in ProAct65+ and helped to facilitate maintenance.

Deterioration in physical health was identified as a barrier to continuation of PA in both groups, this included developing joint problems such as arthritis. Suffering with a cough or cold, lung problems or side effects of prescribed medication were other commonly quoted barriers to maintaining PA.

Reports of witnessing physical deterioration in partners or friends promoted maintenance.

\section{Social facilitators and barriers}

Social interaction emerged as a prominent theme facilitating maintenance of PA amongst FaME participants. The development of friendships in the class setting was repeatedly quoted as an advantage of the class. These friendships were maintained by joining new PA classes with their newly formed friends after the end of the programme, improving participants' social support network.

Enjoyment of the exercise programmes was identified as a key reward promoting feelings of motivation and continuation of PA. Motivating factors specific to FaME included the benefit of having to leave the house for organised 
Table 2 Characteristics of study participants

\begin{tabular}{|c|c|c|}
\hline & Exercise group & \\
\hline & $\begin{array}{l}\text { FaME } \\
n=15\end{array}$ & $\begin{array}{l}\text { OTAGO } \\
n=15\end{array}$ \\
\hline Participant Characteristics & & \\
\hline Female sex, n (\%) & $10(66.7)$ & $12(80.0)$ \\
\hline Mean age, years $[S D]$ Age range, years & $76.47[5.6] 72-88$ & $78.47[5.7] 70-95$ \\
\hline Household, n (\%) & & \\
\hline Lives alone & $5(33.3)$ & $6(40.0)$ \\
\hline Lives with other family members & $0(0.0)$ & $2(13.3)$ \\
\hline Married or living as married & $10(66.7)$ & $7(46.7)$ \\
\hline Employment, n (\%) & & \\
\hline In part time employment & $1(6.7)$ & $0(0.0)$ \\
\hline Homemaker & $0(0.0)$ & $1(6.7)$ \\
\hline Retired & $14(93.3)$ & $14(93.3)$ \\
\hline Minutes of moderate to vigorous physical activity per week ${ }^{\mathrm{a}}$ Mean [SD] & $173[130.5]$ & $177[148.8]$ \\
\hline Range & $0-375$ & $0-540$ \\
\hline At least 150 min moderate to vigorous physical activity per week, n (\%) & $7(46.7)$ & $9(60.0)$ \\
\hline Current level of activity, n (\%) & & \\
\hline I do not do any planned physical activity during the week and would find it difficult to start & $0(0.0)$ & $3(20.0)$ \\
\hline I used to exercise regularly each week but have lapsed & $2(13.3)$ & $0(0.0)$ \\
\hline I exercise once in a while but not weekly & $0(0.0)$ & $4(26.7)$ \\
\hline I exercise regularly each week & $13(86.7)$ & $8(53.3)$ \\
\hline Falls risk ${ }^{\mathrm{b}}$ Median [IQR] & $1.00[0-1]$ & $1.00[0-1]$ \\
\hline Had a fall in the last 12 months & $0(0)$ & $4(26.7)$ \\
\hline Taking 4 or more medications & $7(46.7)$ & $7(46.7)$ \\
\hline History of Parkinson's disease or stroke & $0(0)$ & $1(6.7)$ \\
\hline Balance problems & $4(26.7)$ & $1(6.7)$ \\
\hline Unable to rise from chair of knee height & $0(0)$ & $1(6.7)$ \\
\hline Concern about falling ${ }^{c}$ Mean [SD] & $1[1.5]$ & $1.2[1.3]$ \\
\hline General health: $^{\text {d }}$ & & \\
\hline Excellent & $4(26.7)$ & $3(20)$ \\
\hline Very good & $2(13.3)$ & $1(6.7)$ \\
\hline Good & $5(33.3)$ & $7(46.7)$ \\
\hline Fair & $4(26.7)$ & $4(26.7)$ \\
\hline Poor & $0(0)$ & 0 \\
\hline
\end{tabular}

$S D$ standard deviation, $I Q R$ interquartile range

${ }^{a}$ Community Healthy Activities Model Program for Seniors (CHAMPS) [43]

${ }^{b}$ Falls Risk Assessment Tool (FRAT; range 0-5) [44]

cFalls Efficacy Scale - International [39]

${ }^{d} 12$-Item Short Form Health Survey question: In general would you say your health is... [40]

structured activity. Participants felt they would find distractions within the home environment reducing their commitment to doing the home-based exercises. In addition, motivation was gained by exercising alongside others.

Participants of OTAGO reported they were more likely to maintain PA levels if they lived with a partner, through motivating and encouraging one another. For both groups, positive feedback and evaluation of PA from friends and family contributed to the participants' perception of "normal" levels of PA, influencing subjective norms and maintenance of PA. Maintenance was mainly seen in those who were previously in the habit of exercising before the programme.

Those in caring roles felt this activity made them more physically active, however it also acted as a barrier preventing participation in structured organised PA. 
Table 3 Illustrative extracted quotes

\begin{tabular}{lll}
\hline Themes & Sub themes & Illustrative data extracts \\
\hline Physical & Physical benefits & 'I think once you stop exercising you stiffen up and that then takes a lot \\
& of coming back if you don't keep yourself supple and mobile and well \\
& you become a cabbage'(ID26 Female 75-79years OTAGO)
\end{tabular}

Deterioration in physical health

Health beliefs

Witnessing deterioration in others
I know that it was doing me good because muscles were aching ... and I thought this is doing me good, and if you think it is doing you good, you will continue, won't you?' (ID2 Female 80-84 years OTAGO)

"I was more flexible, I do have a bad back which I have had for erm along... decades'(ID4 Female 70-74 years FAME)

Well you know things like getting... you know getting up out of a chair and things like that' (ID11 Male 70-74 years FAME)

I can't run anymore, the body is willing but the flesh is weak, the legs won't go' (ID12 Female 80-84 years FAME)

I think one thing that has, I have thought about for the elderly and the reason why elderly people don't do exercise is so many of them start going on medication for one thing and another and statins and erm a lot of medication does affect you and makes you feel lethargic and tired and so I think one of the main reasons with the elderly in stopping doing exercises it is tablets' (ID8 Female 75-79 years FAME)

I mean I have got arthritis all over the place, in my spine and in my neck and that sort of erm stops me doing anything too energetic' (ID13 Female 70-74 years FAME)

II am having a little problem with my knees so I don't walk as much as I used to' (ID 23 Female 80-84 years OTAGO)

It is very difficult, you know people over 55, they've started to think they are getting old, and what do I want to do exercise for? Which I can't... that is not in my mind but I can see this in people that I talk to you know of my age you know, what the hell do I want to do exercise for?' (ID5 Male 80-84 years FAME)

'You wonder if it is through doing them that you have got these pains you know' (ID28 Female 75-79 years OTAGO)

'Once you stop ..... it becomes more difficult to start up again' (ID4 Female 70-74 years FAME)

'Oh well I am well in my 70's so you know I have a right to sit down and do nothing. I have got a friend like that and everything I do she says oh I bet you were tired weren't you?' (ID8 Female 75-79 years FAME)

I think seeing how my husband went down so quick, that motivated me more because you can see how quick you do go down' (ID30 Female 75-79 years OTAGO)

'as you get older if you are on your own you need company so there is no company is there sat here? You know what I mean?' (ID28 Female 75-79 years OTAGO)

Yes the social side of it yes because we did... You know when you're retired and not going to work, it is trying to find something else and still meeting people' (ID1 Male 70-74 years FAME)

It was actually one of the people that went to the Pro-Active...... they started going to Tai Chi and it was him that told me about this Tai Chi classes so we enrolled in that, we both enrolled on that so it was you know it was somebody we had met at those classes that talked us in to going or told us about this Tai Chi so we thought we would give it a go and erm like I say because we were all beginners' (ID11 Male 70-74 years FAME)

Motivating factors
You know because I had only recently retired as well so it was thinking of some exercises that I could do or something I could do you know to get me out of the house rather than sitting reading and watching television all the while' (ID11 Male 70-74 years FAME)

'I wasn't sure that I would have the commitment to do it at home, you know, life gets in the way' (ID4 Female 70-74 years FaME)

'I would have rather have gone to the classes because I think it encourages 
Table 3 Illustrative extracted quotes (Continued)

\begin{tabular}{|c|c|c|}
\hline Themes & Sub themes & Illustrative data extracts \\
\hline & \multirow{4}{*}{ Positive feedback from others } & $\begin{array}{l}\text { you more, when you are at home you have got no stimu } \\
\text { (ID30 Female } 75-79 \text { years OTAGO) }\end{array}$ \\
\hline & & $\begin{array}{l}\text { Yes because we're both more or less go to the same type } \\
\text { things and one pushes the other one on shall we say' } \\
\text { (ID27 Male 75-79years OTAGO) }\end{array}$ \\
\hline & & $\begin{array}{l}\text { Yes because we work together, if we're doing anything it } \\
\text { usually done together' (ID26 Female 75-79 years OTAGO) }\end{array}$ \\
\hline & & $\begin{array}{l}\text { 'And I was showing him some of the exercises and it is } \\
\text { when hearing him say that would do you good, now } \\
\text { that would be good for you...' } \\
\text { (ID2 Female 80-84 years OTAGO) }\end{array}$ \\
\hline
\end{tabular}

Habit

'We don't mind doing these Pro-Age 65 exercises, as I say we do them every morning without fail, we always find time for that, then we start to get ready to go out or do a days work whatever' (ID26 Female 75-79 years OTAGO)

'you have got to regiment yourself to do these things haven't you?' (ID29 Female 75-79 years OTAGO)

you get in a routine really and we have such a jolly time that... and I think we all felt that we benefitted hugely, that no it was good' (ID7 Female 70-74 years FAME)

I just carried on doing them because they were asking you how many times you had done them, if one a regular basis with your legs and the weights and all that sort of thing so I just did it and never thinking that this would be coming along now so I did them because they were part of the exercise' (ID20 Female 75-79 OTAGO)

Carer role

Self-efficacy
Well because you have got to be regimented yourself to do these things haven't you? You have got to make sure you do them, my husband was alive then so I had a lot to do looking after him you see so it was a bit difficult at times yes' (ID29 Female 70-74 years OTAGO)

I would have liked to have carried on doing it because filling those papers in as well every month gave you the incentive to do it'. (ID30 Female 75-79 years OTAGO)

'you have got to give them a goal and you have got to let them see that they have achieved something' (ID24 Male 75-79 years FAME)

When there was no record at all required then I just didn't bother doing it' (ID1 Female 70-74 years OTAGO)

"I am used to having... doing things, physically, and on top of that exercising regularly in as an individual................ so I am quite capable of stringing together a programme that would suit me' (ID21 Male 70-74 years OTAGO)

I was at the home, doing the home, I would have rather have gone to the classes because I think it encourages you more, when you are at home you have got no stimulation more or less when you're at home but when you are in a class you try and do the same as everybody else don't you?'

'And it is the company as well when you're on your own, you have not got the company to encourage you, you know I tended to start and do the exercises but after about half an hour, I got a little bit fed up with it so I left it off and then perhaps went back to it the next day. Whereas if you're in a class you do it in one go don't you?' (ID30 Female 75-79 OTAGO)

II suspect that I wouldn't have done the home exercises as consciously as going to the classes, I need somebody there to motivate me and to push me really and the advice' (ID7 Female 70-74 years FAME)

'I think it would have been harder to start with you know, to start with. 
Table 3 Illustrative extracted quotes (Continued)

\begin{tabular}{ll}
\hline Themes & Illustrative data extracts \\
\hline & I am usually pretty motivated anyway, if I take anything on I \\
usually like to continue with it you know but I think the class, \\
it is you know to encourage one another don't you with a \\
group' (IDI9 Female 70-74 years FAME) \\
'My main difficulty is that life gets in the way because we \\
have quite a busy life' (ID4 Female $70-74$ years FAME) \\
'I am a busy person, I do try and fit in as much as I can and \\
as I say I paint and it annoys me when I haven't got enough \\
time to do my painting so you know I like to put some time \\
aside to paint' (ID8 Female 75 -79 years FAME) \\
'I just think I am not that sort of person, I have got enough to \\
do without being you know... taking exercise up. In a while I \\
will have, I have got all of my planting to do, all my pots and \\
things so I don't think anything would encourage me to go to \\
the gym or anything' (ID28 Female 75-79years OTAGO)
\end{tabular}

would have looked to join a class with people, there is a class that is not too far from where I live and I have looked at that once or twice and thought about going but circumstances are that I just haven't got the time.' (ID1 Female 70-74 years OTAGO)

Mental health

Environmental

Convenience

Follow on activity

Technology

Financial

Accessible Transport

Weather

Safety
'I can't go any further and my legs just seize up and I feel mentally tired as well as physically tired' (ID30 Female 75-79 years OTAGO)

I think you can quite easily get depressed when you're really tired so you have to sort of shake your feathers and say oh come on get on with it' (ID6 Female 70-74 years FAME)

You don't always want to be going down town' (ID2 Female 80-84 years OTAGO)

It needs a follow up really if you are wanting to help people getting older because that... it is like taking a step forward and then you just slip back, human nature' (ID18 Male 75-79 years FAME)

Well if you have not used technology in your working life in your life, you're going to find it very difficult to use technology, nowadays aren't you?' (ID29 Female 70-74 years OTAGO)

'it does make you go because you have paid for it in advance' (ID11 Male 70-74 years FAME)

II mean when you have got a pension you do struggle to pay for such as gyms and things like that so if I could find something that was reasonable then I would probably do more' (ID30 Female 75-79 years OTAGO)

yes you need transport, which I have got........ I have got a free bus pass and the buses are only there across the road' (ID28 Female 75-79 years OTAGO)

yes and physically I wasn't driving then so I couldn't get to where they were' (ID10 Female 85-89 years FAME)

Yes I think the weather does, I think you know if it was pouring down with rain or something like that, I would probably be reluctant to go out and walk far in it.'

(ID11 Male 70-74 years FAME)

'Erm... the weather, you know like I was saying if it is not a very nice night you obviously don't go or if it is cold or snow' (ID1 Female 70-74 years OTAGO)

Well you read the media of people being attacked, today there is someone being attacked and phone taken off her, that sort of thing' (ID29 Female 70-74 years OTAGO)

'As long as it is sort of day time and you're not travelling too far' (ID6 Female 70-74 years FAME) 
Barriers identified were similar in both groups, which included lack of time and having a 'busy life', suggesting PA was not a priority. Different reasons were given by participants for a lack of PA, highlighting competing demands on their time. These included attending clubs or social activities which participants felt were beneficial for keeping their minds active and socialising; doing volunteer work or hobbies such as painting, shopping, baking, reading and knitting. A greater emphasis was placed on these activities compared to PA.

\section{Psychological facilitators and barriers}

'A lot of it is motivation' was an important theme identified in PA maintenance. Sources of motivation arose from the perceived convenience, measurable activity, organised structured activity and use of technology.

Measurable activity with pedometers and tick charts were discussed as external motivating factors by participants in both groups. These allowed participants to recognise improvements in their PA levels encouraging and facilitating maintenance. Self-efficacy and development of a positive routine or habit was perceived important in the OTAGO group to maintain PA levels.

There was evidence of health beliefs which discouraged maintenance of PA, these included thoughts of an inevitability of the ageing process ensuing once PA was discontinued and worsening of joint pains secondary to participating in PA.

Mental health and participants' attitudes towards exercise emerged as important themes. Participants felt their attitude or that of others to old age may have a negative impact on PA maintenance. Depression or low mood was a barrier to PA maintenance affecting motivation, resulting in fatigue and higher levels of social isolation. Memory impairment was identified as another important barrier to maintenance.

\section{Environmental facilitators and barriers}

Location and availability of exercise programmes to move onto once FaME or OTAGO had ended were important in maintaining PA. These included proximity to venues offering a range of different types of PA and exercise classes geared specifically towards older adults. When classes already existed, participants sometimes felt lack of advertisement created a barrier to making them aware of them.

Technology provided a source of motivation and encouragement through external feedback. Across both groups individuals reported they used apps on smartphones or pedometers to help maintain PA. Some participants felt it would be difficult to start using technology as they lacked prior experience and cost emerged as a prohibitive factor to using technology.
Transport was considered either a facilitator or the lack of it as a barrier for maintenance. Those that had their own car, commented location of facilities was unimportant. Easy access to a car park increased the likelihood of visiting a facility. A free bus pass meant participants could travel to take part in PA.

The weather had a detrimental impact on participant's PA levels. Wet, snowy and icy weather prevented individuals from participating in PA outside the home, due to a fear of falling. Cold weather was felt to have a negative impact on joint pain, inhibiting PA maintenance.

The timing of classes or planned PA also acted as a barrier to keeping active, with some participants reporting classes were held at inconvenient times of the day. Personal safety was a concern for those attending classes running late into the evening, more important when the days were shorter in the winter months. Conscious efforts were made to time walks during daylight hours. Some individuals felt uneven terrain or hard surfaces stressed their joints acting as a barrier to maintain PA.

Cost or affordability was considered both a facilitator and a barrier. Some participants reported they found it expensive to access local facilities where they had to sign a contract and pay an initial set fee, particularly due to being on a fixed income with a pension. Whereas for others the initial upfront fee, if affordable, promoted maintenance by encouraging a commitment to attending the classes they had already paid for.

\section{Discussion \\ Main findings}

The results of our study show that PA maintenance behaviours in older people are complex with multiple influences. Our findings add to the body of literature for older adults, which is often a neglected group and discussed in the context of well accepted behaviour change theories. Our results showed perceived improvements in physical health, social support and interaction, exercising alongside others, encouragement from friends and family and positive visual feedback all acted as facilitators to PA maintenance. Creating routines and making PA habitual were important for OTAGO participants, whilst making a commitment to attend exercises classes was important for FaME participants. Witnessing a physical deterioration in others, physical or mental health problems, competing interests, poor weather, safety fears, lack of transport and location of facilities all acted as barriers to PA maintenance. Cost was both a facilitator and a barrier to maintaining PA.

\section{Strengths and limitations}

This was a qualitative study of people that participated in a large, randomised controlled trial of usual care versus home and group-based exercises to increase PA and 
reduce falls. Our study provides some explanations as to why strength and balance exercise programmes work to increase physical activity.

Strengths of this study include the large number of interviews conducted allowing thematic saturation, and coding by two researchers. Further coding of some transcripts by a PPI member provided a lay perspective on themes emerging. Interviewer shadowing by both researchers conducting the interviews helped ensure consistency in technique.

This study was subject to certain limitations. Whilst $54 \%$ of those invited to the study expressed interest in participating, deaths and illnesses would have affected who the GP sent invitations to. Those not invited, those not expressing interest, or those expressing interest who were not interviewed, may have differed from those who were interviewed with regards to maintenance of physical activity. We did not have ethical approval to approach those not responding to study invitations, so we were unable to explore their characteristics and reasons for non-response. Interviews were conducted between 4 and 6 years after the end of the ProoAct65+ exercise programme, participants may have recalled facilitators and barriers to PA maintenance more easily if interviews had occurred closer to the end of the exercise programme. However, the findings are similar in content to what is already known about barriers and facilitators to PA maintenance, which might suggest that delayed recall does not alter themes. For individuals who viewed participation in the ProAct65+ trial as a significant life event, as taking part was demanding and intense (in terms of the volume of data collected). And if life was positively changed through the social interaction provided by the FaME programme or increased independence due to improved activities of daily living, then recall could be valid for an extended period of time [45].Social desirability bias may have occurred, as participants may have over reported PA levels and selection bias may have occurred if those who were more PA were more likely to participate. In addition, fewer participants were men and only one participant belonged to a Black \& Minority Ethnic (BME) group, so their views are not well represented in our study.

\section{Comparisons with existing literature}

Several other studies have shown that good physical health status [46-50] and being physically fit [51-53] encourages PA maintenance. These are consistent with our study findings where poor or deteriorating physical health acted as a barrier to PA maintenance.

Our study found those living with a partner reported it supportive for the maintenance of PA. The literature shows a positive association with PA maintenance in those who are married [46, 48, 54]. However, evidence for social support promoting PA maintenance is limited
[50, 53, 55]. Perceived social support received from exercise instructors [56], walking companions, friends and sports exercise group (e.g. volleyball, basketball, aerobics and badminton) members $[32,53]$ has been found to be positively associated with PA maintenance.

Positive mood has been associated with PA maintenance $[49,51]$, and in our study participants reported depression and low mood acting as a barrier. Feelings of safety within the neighbourhood and perceived accessibility of facilities has been positively associated with PA maintenance [57], similar to our study findings.

PA maintenance is problematic, identification and syntheses of existing theory may help us to better understand PA maintenance in older adults, which can be used to inform future intervention development. Our findings are consistent with several theories of behaviour change, although no single theory encompasses all our findings. PA maintenance was facilitated by positive evaluation of its benefits consistent with the theory of planned behaviour (TPB) and regulation theory (RT) [58]. Remaining independent and improving confidence in balance helped maintain autonomy, consistent with the self-determination theory (SDT) $[59,60]$. Perceived susceptibility in terms of the risks individuals faced by not taking part in PA played a role in maintenance; consistent with the health belief model [61]. In contrast, some older people perceived physical deterioration in older age to be inevitable or outside of their control demonstrating a lack of self-efficacy acting as a barrier to maintaining PA, consistent with social cognitive theory (SCT) [62-64] and consistent with other studies self-efficacy findings $[46,47,50,53]$.

Structured organised activity provided greater motivation than home based activities, which may be undertaken alone. In older age, social activities and inclusion become increasingly important due to death of partners and friends, deterioration in health and lack of mobility which can result in social isolation. In our study social interaction featured as a prominent theme for the maintenance of PA. The importance of the social context and environment in promoting behaviour change are well described by the SDT, organismic integration [59] and cognitive evaluation theories (CET) [65]. FaME classes provided this ideal environment, contributing to participant's enjoyment of the classes further supported with peer motivation during classes, resulting in maintenance behaviour consistent with the RT. [66] In addition, positive feedback from peers, family and friends, from having their progress monitored by completing exercise diaries or from using technology such as pedometers facilitated maintenance by reinforcing subjective norms consistent with the CET and TPB [67]. A study [50] following up participants of the PACE-UP trial [68] where pedometers were used to increase walking in adults aged $45-74$ years, 
showed pedometers helped with 'kick-starting' activity and subsequently supported maintenance of PA.

Those in the OTAGO group required higher levels of self-efficacy to maintain PA, this is explained through the social cognitive theory (SCT) [64] and health belief model due to the lack of social support, but had more control (TPB, SDT) over when and how much PA was completed. Where there was failure in development of a routine consistent with the Habit Theory (HT) $[69,70]$ this was often due to lack of prioritisation of PA, conversely development of this contributed to maintenance.

\section{Conclusion}

We have identified a range of factors which, if incorporated into community-based exercise programmes should facilitate exercise maintenance and help commissioners when designing exercise programmes for older adults. To meet the varied needs of older adults and to encourage maintenance of increased levels of PA once exiting local community based exercise programmes, a range of physical activity programme options should ideally be available. This will help older adults choose what, why, when and how to maintain their increased PA. Providing monitoring and feedback [71, 72] and increasing self-efficacy related to PA are important to PA maintenance.

Evidence has shown that social interaction promotes PA maintenance. This could be implemented through 'buddying schemes' with support from group members or exercise partners $[33,53]$ which has been shown to be positively associated with maintenance. Alternatively, the provision of subsidised structured PA classes participants can continue onto may promote maintenance. Signposting to relevant facilities and classes after exercise programmes have ended, has been identified as being important to help facilitate maintenance of PA. The option of organised community transport to PA facilities would address the transport issue for those who report difficulty accessing facilities. For those preferring homebased exercise, ongoing monitoring and peer meetings would support maintenance.

\section{Supplementary information}

Supplementary information accompanies this paper at https://doi.org/10. 1186/s12877-019-1366-x.

\section{Additional file 1. Keeping Active Interview Guide.}

\section{Abbreviations}

CET: Cognitive evaluation theories; HT: Habit theory; PA: Physical activity; PPI: Patient and public involvement; ProAct 65+ trial: Group (FaME) and home based (OTAGO) exercises; RT: Regulation theory; SCT: Social cognitive theory; SDT: Self-determination theory; TPB: Theory of planned behaviour

\section{Acknowledgements}

We would like to thank the practices and older aged adults who took part in our study. We would also like to say thank you to Patricia Overty our PPI representative on the project.

\section{Authors' contributions}

All authors have read and approved the manuscript. AM contributed to the collection and interpretation of the data and drafted the manuscript. NL contributed to study conception and design, obtaining study funding, collecting and interpreting the data, critically reviewing and revising the manuscript. EO was involved in conception and design of the study, obtaining study funding, interpreting data, critically reviewing and revising the manuscript. SI involved in conception and design of study, obtaining study funding, interpreting data, critically reviewing and revising the manuscript. SA contributed to data collection, interpreting the data, critically reviewing and revising the manuscript. KV was involved in conception and design of study, obtaining study funding, interpreting data, critically reviewing and revising the manuscript. DK conceived and designed the study, obtained study funding, supervised data collection and analysis, contributed to interpreting data and critically reviewing and revising the manuscript.

\section{Funding}

National Institute for Health Research (NIHR) School for Primary Care Research, award number 264. Recipient - University of Nottingham. The funding body (NIHR SPCR) had no role in study design, data collection or analysis or data interpretation. They were not involved in the preparation of the manuscript.

\section{Availability of data and materials}

The datasets generated and analysed during the current study are not publicly available as permission was not sought from participants to share interview transcripts.

\section{Ethics approval and consent to participate}

Ethical approval was provided by National Research Ethics Service Committee South East Coast - Surrey (reference number 15/LO/1579). Written consent was obtained from participants.

\section{Consent for publication}

Not Applicable.

\section{Competing interests}

The authors declare that they have no competing interests.

\section{Author details}

${ }^{1}$ School of Medicine, University of Nottingham, Floor 14 Room 1401, Tower building, University Park, Nottingham NG7 2RD, UK. ${ }^{2}$ Research department of Primary Care \& Population Health, University College London, Gower Street, WC1E 6BT London, UK.

Received: 1 January 2019 Accepted: 22 November 2019

Published online: 12 December 2019

\section{References}

1. Tremblay MS, Aubert S, Barnes JD, Saunders TJ, Carson V, Latimer-Cheung AE, et al. Sedentary behavior research network (SBRN)-terminology consensus project process and outcome. Int J Behav Nutr Phys Act. 2017;14(1):75.

2. Public Health England. Physical Activity - Key Indicators. 2019. https:// fingertips.phe.org.uk/profile/physical-activity/data\#page/6/gid/1938132899/ pat/6/par/E12000004/ati/102/are/E10000019/iid/93015/age/298/sex/4. Accessed 01/09/2019.

3. World Health Organization. Global recommendations on physical activity for health. Geneva: World Health Organization; 2010.

4. Lee I-M, Shiroma EJ, Lobelo F, Puska P, Blair SN, Katzmarzyk PT, et al. Effect of physical inactivity on major non-communicable diseases worldwide: an analysis of burden of disease and life expectancy. Lancet. 2012;380(9838):219-29.

5. Bauman AE. Updating the evidence that physical activity is good for health: an epidemiological review 2000-2003. J Sci Med Sport. 2004;7(1):6-19.

6. Swanenburg J, de Bruin ED, Stauffacher M, Mulder T, Uebelhart D. Effects of exercise and nutrition on postural balance and risk of falling in elderly 
people with decreased bone mineral density: randomized controlled trial pilot study. Clin Rehabil. 2007;21(6):523-34.

7. Yates T, Davies M, Gorely T, Bull F, Khunti K. Effectiveness of a pragmatic education program designed to promote walking activity in individuals with impaired glucose tolerance a randomized controlled trial. Diabetes Care. 2009;32(8):1404-10.

8. Biswas A, Oh Pl, Faulkner GE, Bajaj RR, Silver MA, Mitchell MS, et al. Sedentary time and its association with risk for disease incidence, mortality, and hospitalization in adults: a systematic review and meta-analysis. Ann Intern Med. 2015;162(2):123-32.

9. Thorp AA, Owen N, Neuhaus M, Dunstan DW. Sedentary behaviors and subsequent health outcomes in adults: a systematic review of longitudinal studies, 1996-2011. Am J Prev Med. 2011;41(2):207-15.

10. Kyu HH, Bachman VF, Alexander LT, Mumford JE, Afshin A, Estep K, et al. Physical activity and risk of breast cancer, colon cancer, diabetes, ischemic heart disease, and ischemic stroke events: systematic review and doseresponse meta-analysis for the Global Burden of Disease Study 2013. BMJ. 2016;354:i3857.

11. Office of National Statistics. What does the 2011 Census tell us about older people. 2013. https://www.ons.gov.uk/peoplepopulationandcommunity/ birthsdeathsandmarriages/ageing/articles/whatdoesthe2011 censustellusaboutolderpeople/2013-09-06. Accessed 01/12/2016 2016.

12. United Nations Department of Economic and Social Affairs Population Division. World Population Ageing 2015.

13. Be Active, Be Healthy: A Plan for Getting the Nation Moving. London: Department of Health; 2009.

14. Health Survey for England (HSE). Chapter 2 - Physical activity in adults. Health and Social Care Information Centre: Leeds. 2012. http://healthsurvey.hscic.gov. uk/media/1022/chpt-2_physical-activity-in-adults.pdf. Accessed 02/12/2018.

15. Oxford University Press. Stamina. 2018. https://en.oxforddictionaries.com/ definition/stamina. Accessed 02/12/2018 2018

16. Mazzeo RS, Cavanagh P, Evans WJ, Fiatarone M, Hagberg J, McAuley E, et al. Exercise and physical activity for older adults. Med Sci Sports Exerc. 1998; 30(6):992-1008.

17. King AC, Rejeski WJ, Buchner DM. Physical activity interventions targeting older adults: a critical review and recommendations. Am J Prev Med. 1998; 15(4):316-33.

18. United States. Public Health Service. Office of the Surgeon General. Physical activity and health: a report of the Surgeon General. Thorofare: Government Printing Office; 1996.

19. Chase J-AD. Physical activity interventions among older adults: a literature review. Res Theory Nurs Pract. 2013;27(1):53-80.

20. Conn VS, Valentine JC, Cooper HM. Interventions to increase physical activity among aging adults: a meta-analysis. Ann Behav Med. 2002;24(3):190-200.

21. Frost $H$, Haw S, Frank J. Promoting health and wellbeing in later life: interventions in primary care and community settings. Edinburgh: Scottish Collaboration for Public Health Research and Policy; 2010.

22. Müller AM, Khoo S. Non-face-to-face physical activity interventions in older adults: a systematic review. Int J Behav Nutr Phys Act. 2014;11(1):35.

23. Opdenacker J, Boen F, Coorevits N, Delecluse C. Effectiveness of a lifestyle intervention and a structured exercise intervention in older adults. Prev Med. 2008;46(6):518-24.

24. Kerse N, Elley CR, Robinson E, Arroll B. Is physical activity counseling effective for older people? A cluster randomized, controlled trial in primary care. J Am Geriatr Soc. 2005;53(11):1951-6.

25. Teri L, McCurry SM, Logsdon RG, Gibbons LE, Buchner DM, Larson EB. A randomized controlled clinical trial of the Seattle protocol for activity in older adults. J Am Geriatr Soc. 2011;59(7):1188-96.

26. Voukelatos A, Merom D, Sherrington C, Rissel C, Cumming RG, Lord SR. The impact of a home-based walking programme on falls in older people: the easy steps randomised controlled trial. Age Ageing. 2015;44(3):377-83.

27. Leinonen $R$, Heikkinen $E$, Hirvensalo M, Lintunen T, Rasinaho M, Sakari-Rantala $R$, et al. Customer-oriented counseling for physical activity in older people: study protocol and selected baseline results of a randomized-controlled trial (ISRCTN 07330512). Scand J Med Sci Sports. 2007;17(2):156-64.

28. Morey MC, Dubbert PM, Doyle ME, MacAller H, Crowley GM, Kuchibhatla M, et al. From supervised to unsupervised exercise: factors associated with exercise adherence. J Aging Phys Act. 2003;11(3):351-68.

29. Rydwik E, Frändin $K$, Akner G. Effects of a physical training and nutritional intervention program in frail elderly people regarding habitual physical activity level and activities of daily living-a randomized controlled pilot study. Arch Gerontol Geriatr. 2010;51(3): 283-9.

30. Harris T, Kerry SM, Victor CR, Ekelund U, Woodcock A, lliffe S, et al. A primary care nurse-delivered walking intervention in older adults: PACE (pedometer accelerometer consultation evaluation)-lift cluster randomised controlled trial. PLoS Med. 2015;12(2):e1001783.

31. Jancey JM, Lee AH, Howat PA, Burke L, Leong CC, Shilton T. The effectiveness of a walking booster program for seniors. Am J Health Promot. 2011;25(6):363-7.

32. Dubbert PM, Cooper KM, Kirchner KA, Meydrech EF, Bilbrew D. Effects of nurse counseling on walking for exercise in elderly primary care patients. J Gerontol Ser A Biol Med Sci. 2002;57(11):M733-M40.

33. Buman MP, Giacobbi PR Jr, Dzierzewski JM, Morgan AA, McCrae CS, Roberts $\mathrm{BL}$, et al. Peer volunteers improve long-term maintenance of physical activity with older adults: a randomized controlled trial. J Phys Act Health. 2011;8(s2):S257-S66.

34. Rhodes RE, McEwan D, Rebar AL. Theories of physical activity behaviour change: a history and synthesis of approaches. Psychol Sport Exerc. 2018;42:100-9.

35. Iliffe S, Kendrick D, Morris R, Griffin M, Haworth D, Carpenter H, et al. Promoting physical activity in older people in general practice: ProAct65+ cluster randomised controlled trial. Br J Gen Pract. 2015;65(640):e731-e8.

36. Involve N. Briefing notes for researchers: involving the public in NHS, public health and social care research. UK: INVOLVE Eastleigh; 2012.

37. Stapleton C, Hough P, Oldmeadow L, Bull K, Hill K, Greenwood K. Four-item fall risk screening tool for subacute and residential aged care: the first step in fall prevention. Australasi J Ageing. 2009;28(3):139-43.

38. Stewart AL, MILLS KM, King AC, Haskell WL, Gillis D, Ritter PL. CHAMPS physical activity questionnaire for older adults: outcomes for interventions. Med Sci Sports Exerc. 2001;33(7):1126-41.

39. Yardley L, Beyer N, Hauer K, Kempen G, Piot-Ziegler C, Todd C. Development and initial validation of the falls efficacy scale-international (FES-I). Age Ageing. 2005;34(6):614-9.

40. Ware JE Jr, Kosinski M, Keller SD. A 12-item short-form health survey: construction of scales and preliminary tests of reliability and validity. Med Care. 1996:34:220-33.

41. Ritchie J, Lewis J, Nicholls CM, Ormston R. Qualitative research practice: a guide for social science students and researchers. Thorofare: Sage; 2013.

42. Gale NK, Heath G, Cameron E, Rashid S, Redwood S. Using the framework method for the analysis of qualitative data in multi-disciplinary health research. BMC Med Res Methodol. 2013;13(1):117.

43. Stewart AL, Mills KM, King AC, McLellan BY, Roitz KB, Ritter PL. Evaluation of CHAMPS, a physical activity promotion program for older adults. Ann Behav Med. 1997:19(4):353.

44. Nandy S, Parsons S, Cryer C, Underwood M, Rashbrook E, Carter Y, et al. Development and preliminary examination of the predictive validity of the falls risk assessment tool (FRAT) for use in primary care. J Public Health. 2004;26(2):138-43.

45. Stull DE, Leidy NK, Parasuraman B, Chassany O. Optimal recall periods for patient-reported outcomes: challenges and potential solutions. Curr Med Res Opin. 2009;25(4):929-42.

46. Burton LC, Shapiro S, German PS. Determinants of physical activity initiation and maintenance among community-dwelling older persons. Prev Med. 1999;29(5):422-30

47. Resnick B. A longitudinal analysis of efficacy expectations and exercise in older adults. Res Theory Nurs Pract. 2004;18(4):331-44.

48. van Gool CH, Penninx BW, Kempen Gl, Miller GD, van Eijk JTM, Pahor M, et al. Determinants of high and low attendance to diet and exercise interventions among overweight and obese older adults: results from the arthritis, diet, and activity promotion trial. Contemp Clin Trials. 2006;27(3):227-37.

49. Williams P, Lord SR. Predictors of adherence to a structured exercise program for older women. Psychol Aging. 1995;10(4):617.

50. Wahlich C, Beighton C, Victor C, Normansell R, Cook D, Kerry S, et al. 'You started something... then I continued by myself': a qualitative study of physical activity maintenance. Prim Health Care Res Dev. 2017;18(6):574-90.

51. Emery CF, Hauck ER, Blumenthal JA. Exercise adherence or maintenance among older adults: 1-year follow-up study. Psychol Aging. 1992;7(3):466.

52. Rejeski WJ, Brawley LR, Ettinger W, Morgan T, Thompson C. Compliance to exercise therapy in older participants with knee osteoarthritis: implications for treating disability. Med Sci Sports Exerc. 1997;29(8):977-85.

53. Stevens M, Lemmink KA, van Heuvelen MJ, de Jong J, Rispens P. Groningen Active living model (GALM): stimulating physical activity in sedentary older adults; validation of the behavioral change model. Prev Med. 2003;37(6):561-70. 
54. Irwin ML, Tworoger SS, Yasui Y, Rajan B, McVarish L, LaCroix K, et al. Influence of demographic, physiologic, and psychosocial variables on adherence to a yearlong moderate-intensity exercise trial in postmenopausal women. Prev Med. 2004:39(6):1080-6.

55. McAuley E, Jerome GJ, Elavsky S, Marquez DX, Ramsey SN. Predicting long-term maintenance of physical activity in older adults. Prev Med. 2003;37(2):110-8.

56. Oka R, King A, Young DR. Sources of social support as predictors of exercise adherence in women and men ages 50 to 65 years. Womens Health (Hillsdale, NJ). 1995;1(2):161-75.

57. Li F, Fisher KJ, Bauman A, Ory MG, Chodzko-Zajko W, Harmer P, et al. Neighborhood influences on physical activity in middle-aged and older adults: a multilevel perspective. J Aging Phys Act. 2005;13(1):87-114

58. Aizen I. The theory of planned behavior. Organ Behav Hum Decis Process. 1991;50(2):179-211.

59. Deci EL, Ryan RM. The" what" and" why" of goal pursuits: human needs and the self-determination of behavior. Psychol Inq. 2000;11(4):227-68.

60. Deci EL, Ryan RM. Facilitating optimal motivation and psychological well-being across life's domains. Can Psychol/Psychologie Canadienne. 2008;49(1):14.

61. Becker MH. The health belief model and personal health behavior, vol. 4. Thorofare: Slack; 1974.

62. Bandura A. Health promotion by social cognitive means. Health Educ Behav. 2004:31(2):143-64.

63. McAuley E, Blissmer B. Self-efficacy determinants and consequences of physical activity. Exerc Sport Sci Rev. 2000;28(2):85-8.

64. McAuley E, Jerome GJ, Marquez DX, Elavsky S, Blissmer B. Exercise selfefficacy in older adults: social, affective, and behavioral influences. Ann Behav Med. 2003;25(1):1-7.

65. Deci E, Ryan R. Intrinsic motivation and self-determination in human behavior. New York: Springer US; 1985.

66. Higgins ET. Value from regulatory fit. Curr Dir Psychol Sci. 2005;14(4):209-13.

67. Buchan DS, Ollis S, Thomas NE, Baker JS. Physical activity behaviour: an overview of current and emergent theoretical practices. J Obes. 2012;2012:1-11.

68. Harris T, Kerry SM, Limb ES, Victor CR, lliffe S, Ussher M, et al. Effect of a primary care walking intervention with and without nurse support on physical activity levels in 45-to 75-year-olds: the pedometer and consultation evaluation (PACE-UP) cluster randomised clinical trial. PLoS Med. 2017;14(1):e1002210.

69. Lally P, Van Jaarsveld CH, Potts HW, Wardle J. How are habits formed: Modelling habit formation in the real world. Eur J Soc Psychol. 2010;40(6):998-1009.

70. Rothman A, Sheeran P, Wood W. Reflective and automatic processes in the initiation and maintenance of dietary change. Ann Behav Med. 2009;38(1):4-17.

71. National Institute for Health and Care Excellence. Behaviour change: general approaches. Public health guideline [PH6]. 2007.

72. National Institute for Health and Care Excellence. Behaviour change: individual approaches. Public health guideline [PH49]. 2014.

\section{Publisher's Note}

Springer Nature remains neutral with regard to jurisdictional claims in published maps and institutional affiliations.

Ready to submit your research? Choose BMC and benefit from:

- fast, convenient online submission

- thorough peer review by experienced researchers in your field

- rapid publication on acceptance

- support for research data, including large and complex data types

- gold Open Access which fosters wider collaboration and increased citations

- maximum visibility for your research: over $100 \mathrm{M}$ website views per year

At $\mathrm{BMC}$, research is always in progress.

Learn more biomedcentral.com/submissions 